\title{
Diel interactions between prey behaviour and feeding in an invasive fish, the round goby, in a North American river
}

\author{
STEPHANIE M. CARMAN, ${ }^{*}$ JOHN JANSSEN, ${ }^{+}$DAVID J. JUDE ${ }^{\dagger}$ AND MARTIN B. BERG* \\ *Department of Biology, Loyola University Chicago, IL, U.S.A. \\ ${ }^{\dagger}$ School of Natural Resources and Environment, University of Michigan, Ann Arbor, MI, U.S.A.
}

\section{SUMMARY}

1. We studied the diet of the invasive round goby (Neogobius melanostomus) on a diel basis in the Flint River, a warmwater stream in Michigan, U.S.A. Diet and available prey samples were collected seven times over a $24 \mathrm{~h}$ period in four consecutive months. The section of river studied lacked zebra mussels (Dreissena polymorpha), the primary prey of adult round gobies elsewhere in the Great Lakes region.

2. Diet changed on a diel basis with hydropsychid caddisfly and chironomid larvae predominating during the day, chironomid pupae dominating in the evening and heptageniid mayflies dominating at night. Simultaneous study of macroinvertebrate drift suggested that caddisfly and chironomid larvae were most likely picked from submerged rocks, chironomid pupae were most likely taken during their emergent ascent and mayflies were either captured from the drift or picked from rocks.

3. The Flint River lacks a diverse darter (Family: Percidae) and sculpin (Family: Cottidae) fauna and it appears that the round goby has occupied a generalised darter/sculpin niche. Our results indicate that round gobies have the potential to invade successfully riverine systems, particularly those lacking a diverse benthic fish assemblage.

Keywords: exotic species, feeding behaviour, round gobies

\section{Introduction}

Successful invasive species exhibit characteristics which allow them to exploit and quickly flourish in new habitats. These typically include a wide tolerance of environmental factors, rapid maturation, prolific reproductive strategies and a broad diet (Ricciardi \& Rasmussen, 1998). The round goby (Neogobius melanostomus), a small benthic fish native to the Black and Caspian Sea (Ponto-Caspian) area, possesses many of

\footnotetext{
Correspondence: Stephanie M. Carman, New Mexico Department of Game and Fish, PO Box 25112, Santa Fe, NM 87504,

U.S.A. E-mail: scarman@state.nm.us

Present Address: John Janssen, Great Lakes WATER Institute, University of Wisconsin-Milwaukee, 600 East Greenfield Ave, Milwaukee, WI 53204, U.S.A.
}

these characteristics (Jude, 2001). It is euryhaline, aggressive (Dubs \& Corkum, 1996; Janssen \& Jude, 2001) and has an extended reproductive period (Charlebois et al., 2001). These characteristics have enabled it to expand its range in Eurasia, survive a trans-Atlantic ballast voyage and become established in North America in all the Great Lakes and many of their tributaries (Charlebois et al., 1997, 2001; Jude, 2001).

The round goby seems an unlikely candidate for broad success as an invader because it is specialised for feeding on molluscs via its molariform pharyngeal teeth (Kobegenova \& Dzhumaliyev, 1992; Ghedotti, Smihula \& Smith, 1995). Diet studies do not indicate the broad diet characteristic of successful invasive species. In its native region, as well as in areas in Eurasia where it was introduced, the round goby feeds primarily on bivalves (Miller, 1986; Simonovic, Paunovic \& Popovic, 
2001). Young round gobies in the Great Lakes feed primarily on arthropods, although at $50-60 \mathrm{~mm}$ standard length there is an ontogenetic diet shift to mollusks and there is a high degree of overlap in the introduced laucustrine habitats of round gobies and zebra mussels (Jude, Janssen \& Crawford, 1995; French \& Jude, 2001; Janssen \& Jude, 2001). The primary food of adult round gobies is the introduced zebra mussel (Dreissena polymorpha) (Jude et al., 1995; Ray \& Corkum, 1997; French \& Jude, 2001; Janssen \& Jude, 2001).

The invasion into an upstream section of a Michigan stream by the round goby provided an opportunity to study the diet of this specialist molluscivore where bivalve mollusks, including native and zebra mussels, were scarce. In 1996, the round goby was found at sites in two inland rivers in Michigan, the Flint and Shiawassee Rivers, which drain into Saginaw Bay, Lake Huron. The round goby was presumably transferred via bait buckets to these sites by anglers, as the connection to Lake Huron is far downstream and interrupted by several dams. By 1997, the round goby was confirmed to have established populations in these rivers (Jude \& Janssen, unpubl. data). These invasions are of particular interest because there was no substantial zebra mussel population present during the late 1990s.

In preliminary sampling in the Flint River in 1997 (Jude \& Janssen, unpubl. data), the round goby was most abundant in riffles, a habitat usually dominated by darters (Family: Percidae) and sculpins (Family: Cottidae). The round goby is morphologically similar to darters and sculpins and has been shown to adversely affect these native benthic fish in the Great Lakes (Jude et al., 1995; French \& Jude, 2001; Janssen \& Jude, 2001; Jude, 2001). Preliminary diet analyses indicated that the round goby diet in the Flint River was similar to native stream benthivore diets, consisting of Chironomidae (Diptera) and Hydropsychidae (Trichoptera) larvae and Heptageniidae (Ephemeroptera) nymphs.

In North American benthic feeding fish guilds, food resources are partitioned by foraging habitat, feeding behaviour and time of day (Ross, 1986; Greenberg, 1991). When an exotic species invades a community with closely partitioned resources, the existing food and space resources are reduced, which can lead to elimination of native species (Moyle, Li \& Barton, 1986). To predict the effect of an exotic fish species on an existing assemblage, it is essential to understand use of food resources by the invading fish, including the primary prey and feeding ecology. This will allow for better predictions of the effects the invader will have in other localities and on native fish and invertebrate species. This is of particular interest for the round goby, which is expected to continue to spread in North America, including the Mississippi River system.

The goal of this study was to describe the diet of the round goby in the Flint River. Because fish feeding and prey availability vary temporally, fish diets need to be described on a diel and seasonal basis. Feeding ecology is best described if samples are taken frequently throughout the 24-h period (Johnson \& Dropkin, 1993), particularly at changes in light intensity when feeding activity is often at its peak (Keast \& Welsh, 1968).

We addressed three primary questions regarding this invader. (i) What is the diet of round gobies in the Flint River, a habitat devoid of zebra mussels? (ii) What are the characteristics of the prey of round gobies? (iii) What is the feeding behaviour of the round goby as revealed by changes in their prey choice on a diel basis? These questions are cast in broader questions of whether one invader facilitates the success of other invaders (Simberloff \& Von Holle, 1999) and the adaptability of the Gobiidae.

\section{Methods}

Study site

This study was conducted in the Flint River, a warmwater stream in central Michigan (Leonardi \& Gruhn, 2001). The study site was at the intersection of the river and Irish Road in Genesee County $\left(46^{\circ} 06^{\prime} \mathrm{N}\right.$, $\left.83^{\circ} 32^{\prime} \mathrm{W}\right), 3.9$ river-km downstream from Holloway Dam and 3.1 river-km upstream from Mott Dam. The study site was primarily riffle habitat with depths to $1.2 \mathrm{~m}$ and a mean width of $30 \mathrm{~m}$. Substrate was primarily cobble on sand with some areas of aquatic macrophyte beds (Potamogeton spp.). Discharge ranged from 21 to $60 \mathrm{~m}^{3} \mathrm{~s}^{-1}$ during the study (data from USGS gauging station no. $041475002.8 \mathrm{~km}$ upstream) and was controlled by the upstream dam.

\section{Diel diet collections}

Diel collections of round gobies were made monthly from May to August 1998. To determine peak feeding 
times, samples were collected six times throughout a 24-h period on 16/17 May, 28/29 June, 30/31 July and 22/23 August (Table 1). Samples were collected midafternoon, pre- and post-sunset, middle of the night, pre- and post-dawn and late morning (Table 1). Collection of fishes took approximately $30 \mathrm{~min}$ at each interval.

Collection methods varied with the number of volunteers available. In May, fish were collected by kick-seining into a $4.7-\mathrm{m}$ long by $1.4-\mathrm{m}$ high bag seine with 6-mm bar mesh (Jude \& DeBoe, 1996). Fish samples in June and July were collected with a Coffelt Variable Voltage Pulsator backpack electro-shocker (model BP-2; Coffelt Manufacturing, Flagstaff, AZ, U.S.A.), which was used to drive fish into a bag seine placed immediately downstream. In August, fish were collected by pulling a $3-\mathrm{m}$ by $1.3-\mathrm{m}, 6-\mathrm{mm}$ mesh seine downstream into a stationary bag seine $(6-\mathrm{m}$ by $1.3 \mathrm{~m}$, 6-mm mesh). Regardless of the methods used, collections continued until at least 10 round gobies $>50 \mathrm{~mm}$ standard length (SL; approximately the size at which diet shift to molluscs usually occurs) were obtained. All round gobies collected were killed and preserved in $70 \%$ ethanol. Too few individuals of other fish species were collected for meaningful diet comparisons.

For each sampling date and time, standard length $(\mathrm{mm})$ and sex of 10 round gobies $>50 \mathrm{~mm}$ SL were recorded and stomach contents were removed by dissection for examination in the laboratory. Because the goal of this study was to characterise the feeding behaviour of round gobies by examination of prey, volume or mass of stomach samples were not recorded, as in energetic diet studies. Food items were identified to the lowest practical taxon and counted under a stereomicroscope. For partial prey items, head capsules were counted.

\section{Benthic and drifting invertebrate collections}

Drift and benthos were sampled each time fish were collected. These samples were not intended to quantify rigorously prey abundance, but rather were semiquantitative to determine prey availability in either the drift or the benthos. Before each fish collection, benthos was sampled by collecting five similarly sized rocks from the riffle. Immediately, rocks were placed in plastic pans to contain invertebrates, which were removed by hand using forceps. Drift was collected with a $0.25-\mathrm{m}$ diameter, circular drift net with $363-\mu \mathrm{m}$

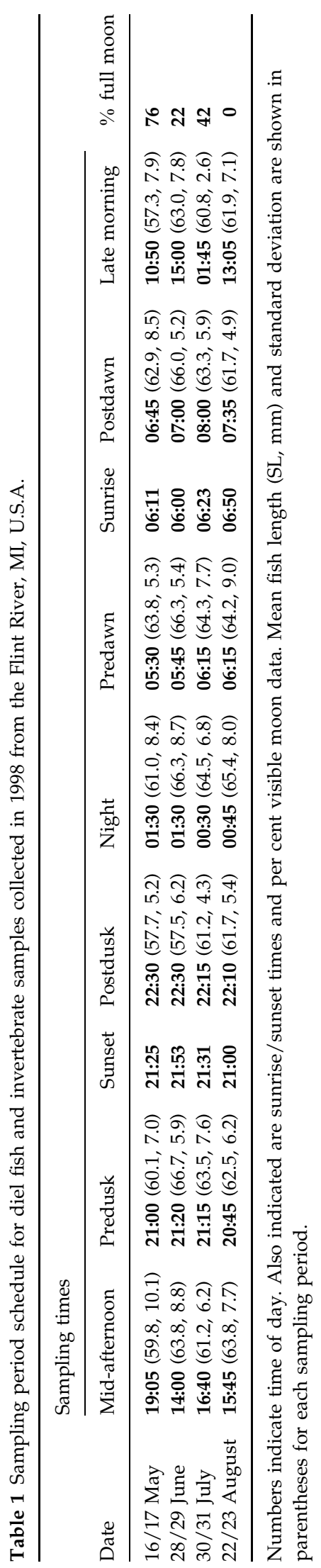

(C) 2006 Blackwell Publishing Ltd, Freshwater Biology, 51, 742-755 
mesh mounted on the substrate using steel rods immediately upstream of the riffle. The net was cleaned and replaced after each fish collection to collect the suite of drifting species in water column available to round gobies prior to the next dietsampling period. Because the length of time between diet sampling periods varied based on crepuscular events, nets were set for 1-6 h. All invertebrates collected were preserved in $70 \%$ ethanol. Invertebrates from rock and drift samples were identified to the lowest practical taxonomic level and counted. Abundance in drift samples was expressed as a capture rate (number $\mathrm{h}^{-1}$ ). Because of sampling difficulties, a benthos sample was not collected during the mid-afternoon period in May and drift samples were not collected during the mid-afternoon periods in May and June.

\section{Statistical analysis}

The five most frequent prey items found in round goby diel diet samples were used for statistical analysis: larval Chironomidae and Hydropsychidae, Chironomidae pupae, Heptageniidae nymphs and Daphnia (Cladocera). For the diel diet data, 280 fish were used (four dates, seven time periods, ten fish each time). The primary purpose of the diel collections was to test for diel patterns in the diet, which were expected to reflect prey activity and availability and therefore to have a peak sometime during the sampling period. To test for feeding peaks, i.e. curvature in prey abundance in stomachs as a function of time, a parabolic approximation in Analysis of Covariance (ANCOVA) was used. Time $(t)$ and time-squared $\left(t^{2}\right)$ (henceforth curvature) were covariates and date was a group effect for each of the main prey taxa. A significant curvature effect would indicate a diel feeding cycle that could be approximated by a parabola. A significant time effect (an overall slope in the data) is probably best interpreted as the parabola being non-symmetrical, i.e. not centred with respect to sampling times. A significant date effect would indicate significant differences among dates.

When curvature was statistically significant, regression was used to approximate the pattern of the diel feeding cycle. This resulted in the following equation describing the number of each prey item in the diet $(y)$ :

$$
y=a t^{2}+b t+c
$$

where $c$ is a constant, and $a$ and $b$ are the coefficients of each time term. This equation statistically demonstrated the presence of a maximum or minimum for each prey. For example, with sampling beginning and ending during the day, a negative curvature coefficient (a) indicated nocturnal feeding, whilst a positive coefficient indicated a daytime feeding maximum. If the date term was significant in the ANCOVA, indicating differences in the diel pattern among dates, a separate regression test was conducted for each date. All statistical analyses were performed using SYSTAT 5.03 (1993).

These analyses required some preliminary examination of the data to determine the location of the maximum or minimum. Because the ANCOVA analysis was designed to test for one maximum or minimum for each prey item, it was unable to test for both a maximum and a minimum as would occur if the feeding cycle was not centred. Chironomid pupae and heptageniid nymphs had night-time peaks with the lowest numbers of prey occurring in mid-afternoon and just before sunset. For these taxonomic groups, the mid-afternoon sample was removed from the data set $(n=240$ fish) to centre better the parabolas. Diel diet data on hydropsychid larvae and heptageniid nymphs as prey were transformed using $\ln (x+1.0)^{2}$ to remove heteroscedasticity and non-normality of errors. Chironomid pupal data were transformed using $\ln (x+1.0)$ to correct for heteroscedasticity.

Daphnia were present in the diet samples only in May and showed no diel pattern. Therefore, Daphnia data were analysed using an analysis of variance (ANOVA), with time of day as the independent variable.

To document changes in the availability of prey items across dates, numbers of invertebrates present in benthic and drift samples were analysed with a two-factor (month and time of day) ANOVA. Tukey pairwise comparison tests followed for significant factors. For Daphnia, hydropsychid larvae, chironomid pupae and heptageniid nymph drift data, $\ln (x+0.5)$ transformations corrected for heteroscedasticity of errors.

\section{Results}

During May through August 1998, 2038 fish were collected from the Flint River. Round gobies were the most common fish species collected (79\% of total), 
followed by emerald shiners (Notropis atherinoides) $(9 \%)$, bluntnose minnows (Pimephales notatus) (3\%), blackside darters (Percina maculata) (2\%) and bluegill sunfish (Lepomis macrochirus) $(2 \%)$. The round gobies used for stomach analysis ranged from 54 to $82 \mathrm{~mm}$ SL with a mean length of $63 \mathrm{~mm}$. Forty-six per cent of the round gobies used for diet analyses were male.

\section{Diel diet patterns}

The most common round goby prey items by number, pooled across all diel periods and months, were chironomid larvae ( $45 \%$ of diet), hydropsychid larvae $(7 \%)$, chironomid pupae $(4 \%)$ and heptageniid nymphs (2\%; Table 2). Daphnia, although present in only 1 month, accounted for $78 \%$ by number of the diet in May and were thus considered an important prey item. Fish prey comprised $<1 \%$ by number of the round goby diet. Only one small round goby (about $30 \mathrm{~mm} \mathrm{SL}$ ) and one small stonecat (Noturus flavus), ( $<25 \mathrm{~mm}$ SL) a common madtom species, were found in stomach samples. Several males were found with round goby eggs in their stomach.

Although round gobies fed throughout a 24-h period, prey type changed during the period (Fig. 1). Across the months, the maximum number of chironomid and hydropsychid larvae occurred in the diet most often during the day, whilst maxima for chironomid pupae and heptageniid nymphs occurred at night. Consumption of Daphnia exhibited diel changes but without a pattern related to the diel cycle.

For chironomid larvae, date, time and curvature were significant $\left(F_{3,274}=23.4, P<0.001 ; F_{1,274}=48.7\right.$, $P<0.001 ; F_{1,274}=35.6, P<0.001$, respectively). The by-date regressions showed similar patterns, generally with a negative time coefficient (from -55.8 to -11.7 ) and positive curvature coefficient (from 0.002 to 0.02), indicating fewest chironomid larvae were found in the diet shortly after midnight (Fig. 2). The curvature was more pronounced in June, July and August, than May, when the fewest number of chironomid larvae were found in stomachs.

Hydropsychid larvae in round goby stomachs were fewest at night (Fig. 3). The ANCOVA revealed that date, time and curvature were significant $\left(F_{3,273}=\right.$ $15.8, P<0.001 ; F_{1,273}=12.9, P<0.001 ; F_{1,273}=21.4$, $P<0.001$, respectively). The by-date regressions indicated that the night-time minimum was more
Table 2 Per cent composition by number of items in the diet of round gobies pooled from collections on 16/17 May, 26/27 June, 30/31 July and 22/23 August 1998 from the Flint River

\begin{tabular}{|c|c|c|c|}
\hline Taxa & Diet & $\begin{array}{l}\text { Benthic } \\
\text { samples }\end{array}$ & $\begin{array}{l}\text { Drift } \\
\text { samples }\end{array}$ \\
\hline \multicolumn{4}{|l|}{ Ephemeroptera } \\
\hline Baetidae nymphs & $<1$ & 0 & $<1$ \\
\hline Heptageniidae nymphs & 2 & $<1$ & $<1$ \\
\hline $\begin{array}{l}\text { Tricorythidae and } \\
\text { Caenidae nymphs }\end{array}$ & $<1$ & 3 & $<1$ \\
\hline $\begin{array}{l}\text { Potamanthidae and } \\
\text { Ephemeridae nymphs }\end{array}$ & $<1$ & $<1$ & $<1$ \\
\hline \multicolumn{4}{|l|}{ Odonata } \\
\hline $\begin{array}{l}\text { Calopterygidae/ } \\
\text { Coenagrionidae naiads }\end{array}$ & $<1$ & $<1$ & $<1$ \\
\hline \multicolumn{4}{|l|}{ Orthoptera } \\
\hline Gryllotalpidae & $<1$ & $<1$ & 0 \\
\hline \multicolumn{4}{|l|}{ Plecoptera } \\
\hline Nemouridae nymphs & $<1$ & $<1$ & $<1$ \\
\hline \multicolumn{4}{|l|}{ Hemiptera } \\
\hline Corixidae & $<1$ & $<1$ & $<1$ \\
\hline \multicolumn{4}{|l|}{ Megaloptera } \\
\hline Sialis & $<1$ & $<1$ & $<1$ \\
\hline \multicolumn{4}{|l|}{ Trichoptera } \\
\hline Hydropsychidae larvae & 7 & 3 & $<1$ \\
\hline Ueniodae (Neophylax) larvae & 0 & 10 & 0 \\
\hline Other Trichopteran larvae & $<1$ & $<1$ & $<1$ \\
\hline Trichopteran pupa & $<1$ & $<1$ & $<1$ \\
\hline \multicolumn{4}{|l|}{ Coleoptera } \\
\hline Elmidae larvae and adult & $<1$ & $<1$ & $<1$ \\
\hline \multicolumn{4}{|l|}{ Diptera } \\
\hline Chaoborus larvae and pupae & $<1$ & 0 & $<1$ \\
\hline Chironomidae larvae & 45 & 82 & $<1$ \\
\hline Chironomidae pupae & 4 & 1 & 2 \\
\hline Simuliidae larvae and pupae & 1 & $<1$ & $<1$ \\
\hline \multicolumn{4}{|l|}{ Others } \\
\hline Daphnia (May only) & $37(78)$ & $<1(<1)$ & $38(33)$ \\
\hline Eubosmina & $<1$ & 0 & 2 \\
\hline Leptodora & 0 & 0 & $<1$ \\
\hline Calanoida & $<1$ & 0 & 5 \\
\hline Cyclopoida & $<1$ & 0 & 51 \\
\hline Arachnida (water mites) & $<1$ & $<1$ & $<1$ \\
\hline $\begin{array}{l}\text { Neogobius melanostomus } \\
\text { (Round goby) }\end{array}$ & $<1$ & 0 & 0 \\
\hline Neogobius melanostomus eggs & $<1$ & 0 & 0 \\
\hline Noturus flavus (Stonecat) & $<1$ & 0 & 0 \\
\hline
\end{tabular}

Also shown is the percent composition of organisms in benthos and drift samples collected at the same time $\left(N_{\text {Fish }}=280\right.$; $N_{\text {Benthos }}=27 ; N_{\text {Drift }}=26$ ). Daphnia percent compositions for $16 / 17$ May collections are given in parenthesis $\left(N_{\text {Fish }}=70\right.$; $N_{\text {Benthos }}=6 ; N_{\text {Drift }}=6$ ).

pronounced in July and August, when hydropsychids were most common in the diet.

The maximum number of chironomid pupae in round goby stomachs occurred at night and ANCOVA revealed significant time and curvature covariates 


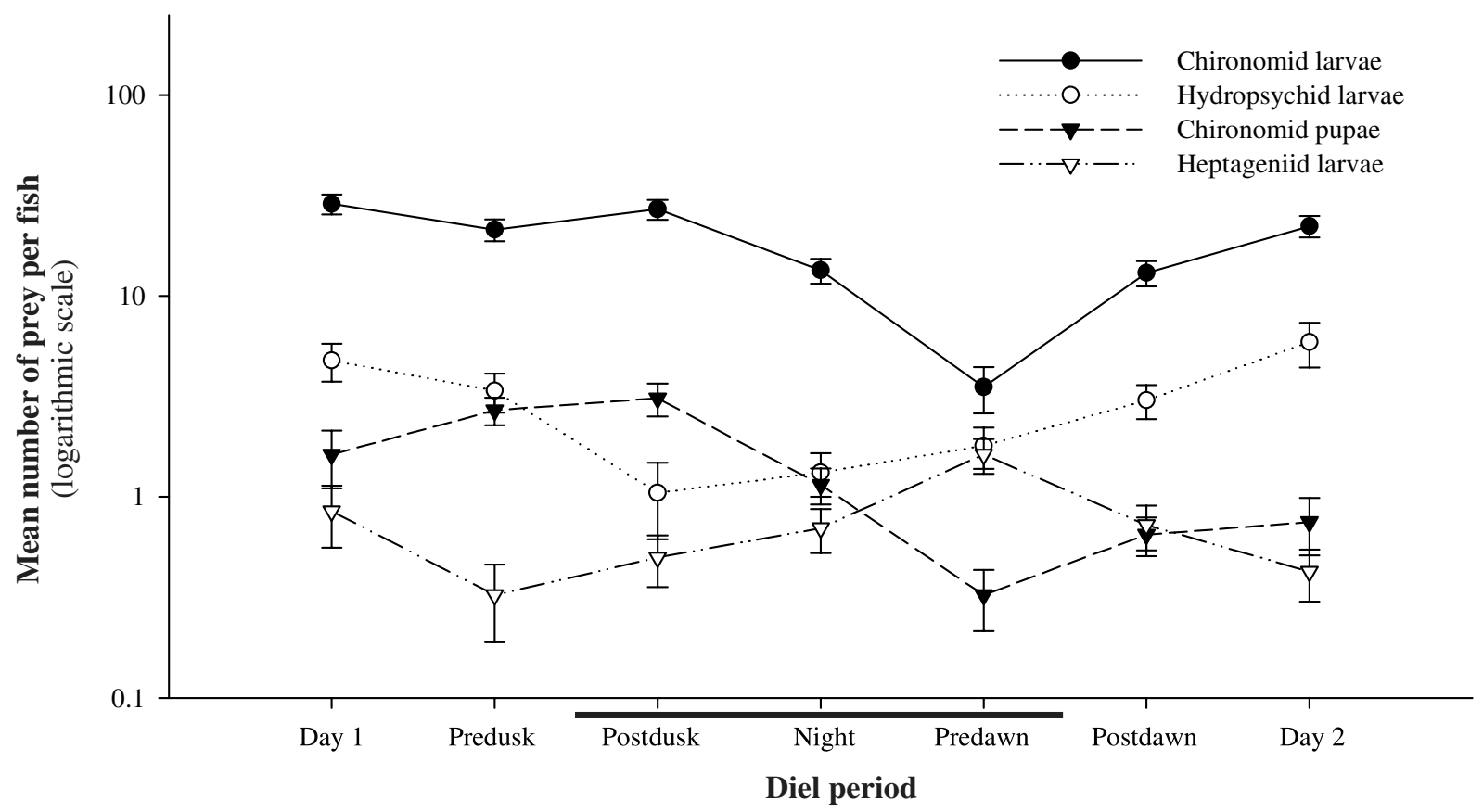

Fig. 1 Diel cycle of main prey items in diets of the round goby collected on 16/17 May, 28/29 June, 30/31 July, and 22/23 August 1998 from the Flint River. The mean number eaten per fish \pm standard error is plotted on a logarithmic scale $(n=280$ fish). The horizontal black bar along the bottom indicates night.

$\left(F_{1,233}=40.7, \quad P<0.001 ; \quad F_{1,233}=20.4, \quad P<0.001\right.$, respectively), with no significant date effect $\left(F_{3,233}=\right.$ 2.0, $P>0.1$ ) (Fig. 4). The regression had a positive curvature coefficient (0.001), indicating the number of chironomid pupae in the diet was greatest in the evening and early morning.

The ANCOVA for heptageniid prey in the diet revealed significant date, time and curvature $\left(F_{3,233}=\right.$ $7.9, P<0.001 ; F_{1,233}=18.4, P<0.001 ; F_{1,233}=15.8$, $P<0.001$, respectively). The by-date regressions showed a nocturnal maximum near midnight with a negative curvature coefficient, ranging from -0.001 to -0.004 (Fig. 5). The nocturnal peak was more pronounced in May, June and July, when heptageniids were more common in the diet.

Daphnia were present in the round goby diet in high numbers only in May (Fig. 6), when there was a significant time of day difference (ANOVA: $F_{6,63}=3.7$, $P=0.003)$, but with no apparent diel cycle because peaks occurred during both day and night.

\section{Benthic invertebrates}

The most abundant benthic invertebrates found on rock samples were chironomid larvae $(82 \%$ by num- ber), Neophylax (Trichoptera; 10\%), hydropsychid larvae $(3 \%)$, Tricorythidae and Caenidae nymphs (Ephemeroptera; $1 \%)$ and chironomid pupae (1\%; Table 2). There were no significant monthly differences (ANOVA 3,17 d.f., $P>0.05$ ) or time-of-day differences (ANOVA 6,17 d.f., $P>0.05$ ) for chironomid and hydropsychid larvae, chironomid pupae and heptageniid nymphs in the benthic samples.

\section{Drifting invertebrates}

The most common invertebrates found in drift samples were Cyclopoida ( $51 \%$ of total drift), Daphnia $(38 \%)$, Calanoida (5\%), Eubosmina (2\%) and chironomid pupae (2\%; Table 2). Although the relative abundance of chironomid and hydropsychid larvae and heptageniid nymphs in the drift was low when compared with the large number of zooplankton present, their importance in the diet of the round goby necessitated their examination in drift samples.

The number of chironomid larvae in the drift was greater in July than May (ANOVA: $F_{3,16}=3.8, P=$ 0.032). No significant time of day effect (ANOvA: $F_{6,16}=1.2, P=0.366$ ) was seen for chironomid larvae in the drift (Fig. 7a). Hydropsychid larval abundance 

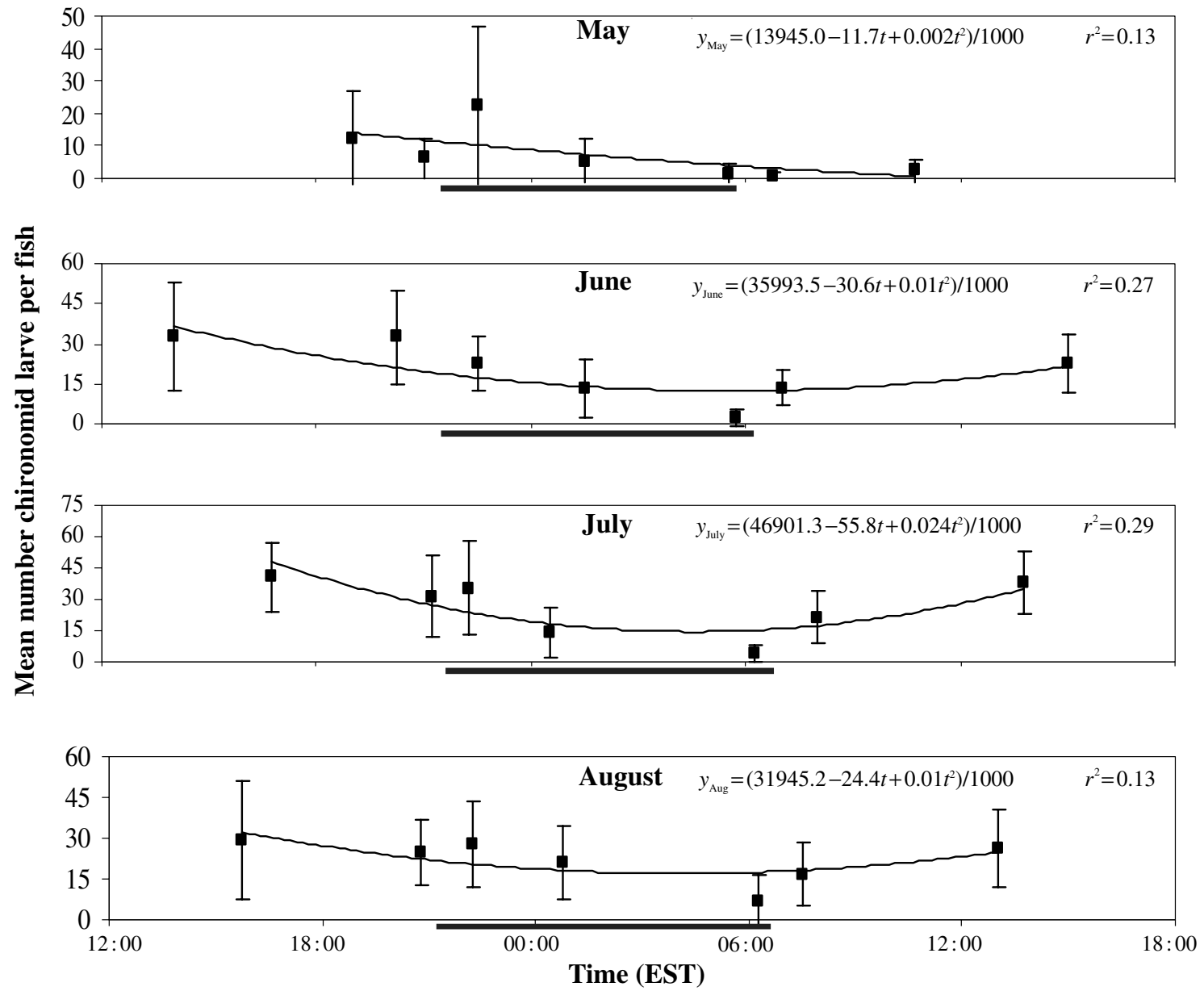

Fig. 2 Chironomidae larvae in diets of the round goby from the Flint River on a diel basis by date (16/17 May, 28/29 June, $30 / 31$ July, and 22/23 August 1998). For all graphs, horizontal black bars along the bottom indicate night. Points are the mean number per stomach \pm standard deviation $\left(n=10\right.$ fish). Curves represent the regression curve for each month where $t=$ time factor, $t^{2}=$ curvature factor. ANCOVA results: date $F_{3,274}=23.4, P<0.001$; time $F_{1,274}=48.7, P<0.001$; curvature $F_{1,274}=35.6, P<0.001$.

in the drift was greater in July than in May or June (ANOva: $F_{3,15}=4.5, P<0.025$ ). Although there was a significant time-of-day effect (ANOVA: $F_{6,15}=3.7$, $P<0.025)$, the Tukey test did not detect any significant pairwise differences (Fig. $7 \mathrm{~b}$ ). The trend was for hydropsychid larvae to be more frequent in the drift at night than during the day. Chironomid pupae in the drift were greater in abundance in July and August than in May (ANOVA: $F_{3,15}=3.4, P<0.05$ ). On a diel basis, the number of chironomid pupae in the drift tended to be greater at night than at other times (ANOvA: $F_{6,15}=4.9, P<0.01$; Fig. 7c). Heptageniid nymphs in the drift were greater in abundance in July and August than in May (ANOvA: $F_{3,15}=5.23$, $P<0.05)$ and were more common in the drift at night than during the day (ANOvA: $F_{6,15}=10.71, P<0.001$;
Fig. 7d). Daphnia numbers in the drift were greater in May and July than June and August (ANOVA: $F_{3,15}=$ 41.43, $P<0.001$ ). Daphnia also showed a significant time-of-day effect (ANOVA: $F_{6,15}=2.78, P<0.05$ ), with a small increase at night, but a Tukey pairwise comparison test did not detect any significant differences among specific times (Fig. 7e).

\section{Discussion}

Our study of the diel feeding of the invasive round goby is of general interest for two reasons. First, the family Gobiidae is extremely speciose, with 1875 described species (Nelson, 1994). Most of these species are marine, so the nature of the invasion of a freshwater stream by the round goby may be of a 


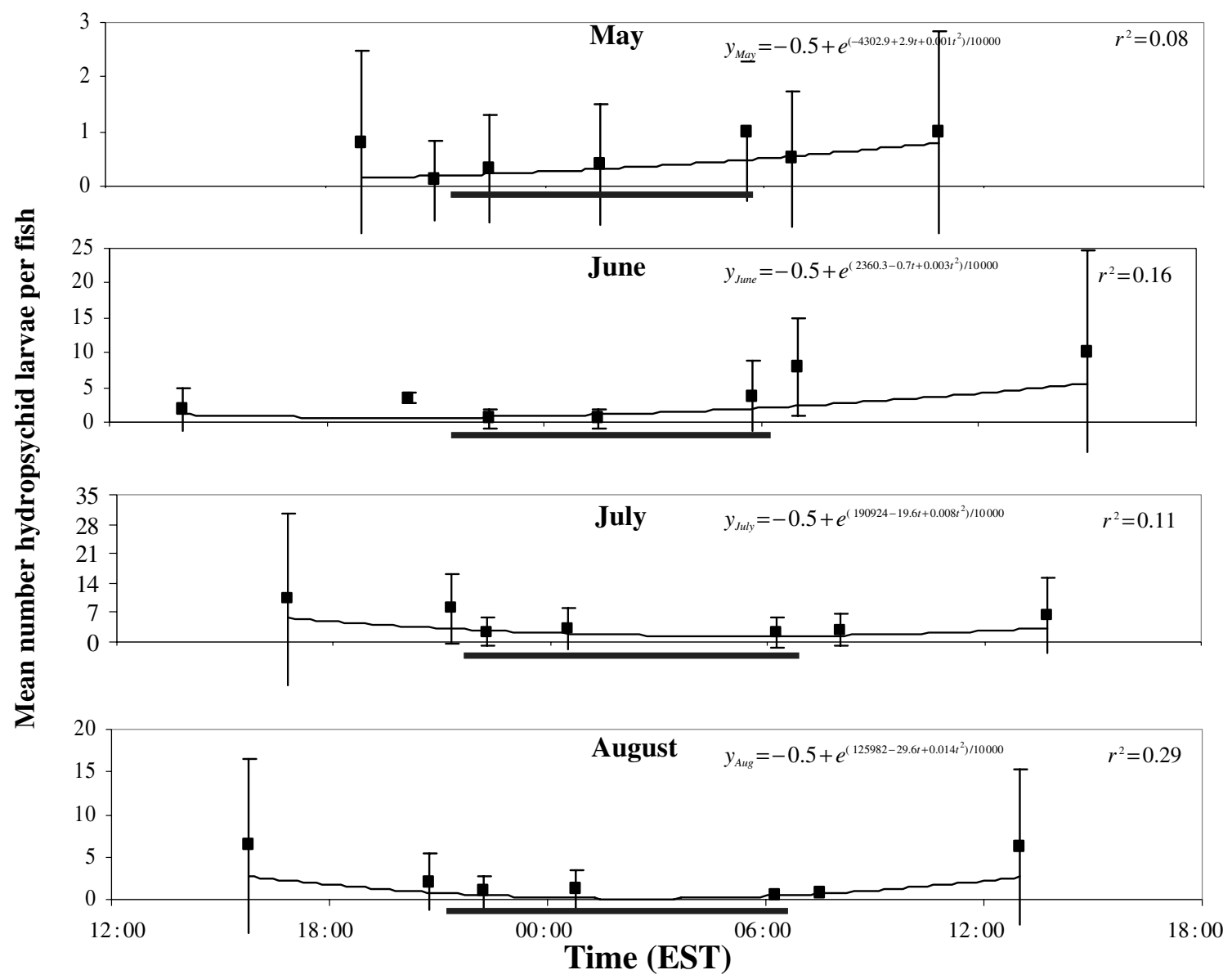

Fig. 3 Hydropsychidae larvae in diets of the round goby from the Flint River on a diel basis by date (16/17 May, 28/29 June, 30/31 July, and 22/23 August 1998). For all graphs, horizontal black bars along the bottom indicate night. Points are the mean number per stomach \pm standard deviation $\left(n=10\right.$ fish). Data were $\ln (x+1.0)^{2}$ transformed for analysis, then back-transformed for the graphs. Curves represent the regression curve for each month, where $t=$ time factor and $t^{2}=$ curvature factor. ANCOVA results: date $F_{3,273}=$ $15.8, P<0.001$; time $F_{1,273}=12.9, P<0.001$; curvature $F_{1,273}=21.4, P<0.001$.

different character that an invasion by a member of a more typically freshwater family. Second, the round goby is one of a growing number of Ponto-Caspian invaders in North America, so our investigation is pertinent to the concept of an 'invasional meltdown' whereby one invader facilitates the success of other invaders (Simberloff \& Von Holle, 1999). Before addressing these broader issues, we consider our results in the context of the study area.

In the absence of zebra mussels as a potential prey, the diet of the round goby in the Flint River appears to be similar to that of native North American stream benthic fishes such as darters and sculpins, which prey primarily on aquatic insects and other arthropods. Types of prey chosen and patterns of occurrence in the diet can reveal much about the feeding behaviour of a predator (Laughlin \& Werner, 1980). In lotic systems interpretation is complicated by nocturnal drift by some prey species. A prey that is benthic in habit may be captured either from the substrate or in the water column whilst drifting.

Types of prey items found in the round goby diet indicate that they were primarily benthic insect feeders in the Flint River. However, items in the round goby diet did not proportionally match items that were available in benthic samples. In fact, some items found in the diet (e.g. Daphnia) did not occur in the benthos, but were found in the drift. Hence it appears that the round goby was not feeding exclusively on benthic prey. Prey of the round goby also varied on a diel basis. Round goby diet breadth, shown both temporally (diurnal and nocturnal feeding) and spatially 


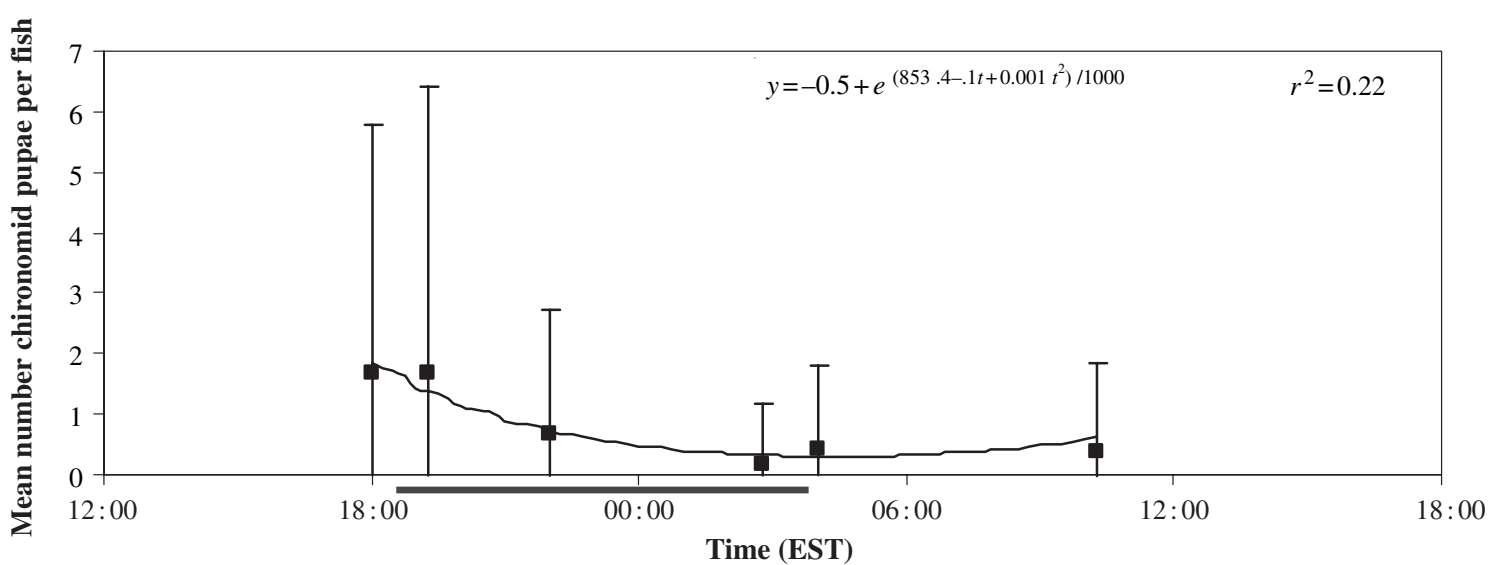

Fig. 4 Chironomidae pupae in diets of the round goby from the Flint River on a diel basis with dates (16/17 May, 28/29 June, 30/31 July, and 22/23 August 1998) combined. The horizontal black bar along the bottom indicates night. Points are the mean number per stomach \pm standard deviation $(n=10$ fish). Data were $\ln (x+1.0)$ for the analysis, then back-transformed for the graph. The curve represents the regression curve for the 4 months combined, where $t=$ time factor and $t^{2}=$ curvature factor. ANCOVA results: date $F_{3,233}=2.0, P=0.11$; time $F_{1,233}=40.7, P<0.001$; curvature $F_{1,233}=20.4, P<0.001$.

(prey taken from the benthos and drift), indicates that the round goby may act functionally in multiple ways in the Flint River. Understanding the functional feeding of round gobies, instead of only what they eat, permits deeper examination of potential competition with other species and impacts on the environment (Matthews, 1998).

During the day, the round goby fed primarily on chironomid and hydropsychid larvae, most likely whilst these were attached to rocks. These prey taxa drift primarily at night (Tanaka, 1960; Bergey \& Ward, 1989) and our own drift samples showed a similar pattern. Both hydropsychids and many chironomid larvae build shelters and/or feeding structures that are exposed to the current and occupy these structures during both day and night.

Two prey taxa, chironomid pupae and heptageniid nymphs, were found in the diet primarily at night, indicating that active feeding is still occurring after nightfall. Chironomid pupae generally emerge at dusk, bursting from their pupal cases, leaving the substrate and floating to the surface for adult eclosion (Pálmen, 1955). Because the number of chironomid pupae in the diet increased immediately at dusk, yet the peak in drift appeared after dusk, it appears that round gobies fed on this prey as they were leaving, or preparing to leave, the substrate.

Heptageniid nymphs are photonegative and hide beneath rocks during the day. They move to the tops of rocks to forage at night (Lyman, 1945; Elliott, 1968), at which time they are more exposed to predation. In the Flint River, an increase was seen in the number of heptageniid nymphs in the drift at night, coinciding with this behaviour. The increase in heptageniids in the diet at night indicates that round gobies fed on these prey when the nymphs were most exposed, either atop rocks or in the water column.

Probably the clearest indication that round gobies will feed on drift during day or night is the occurrence of Daphnia in their diet. Zooplankton were abundant only in drift samples, presumably flowing downstream from the Holloway Dam impoundment. Their irregular diel pattern in May drift samples is probably a consequence of emigration from the upstream impoundment during nocturnal vertical migration, compounded by the time needed to drift to our study site. This effect could be complicated further by temporary residency in upstream pools. Based on this observation, feeding on heptageneiids and / or chironomid pupae while they are adirft is very likely and it is unclear whether they are captured from benthic surfaces.

Similar feeding on zooplankton escaping from a lake was reported for the white sucker (Catostomus commersoni) by Saint-Jacques, Harvey \& Jackson (2000). Although white suckers are morphologically adapted for benthic feeding, zooplankton comprised over half of their diet. It was suggested that white suckers used this resource when benthic prey decreased in abundance or availability. Zooplankton may serve a similar function for round gobies in the 

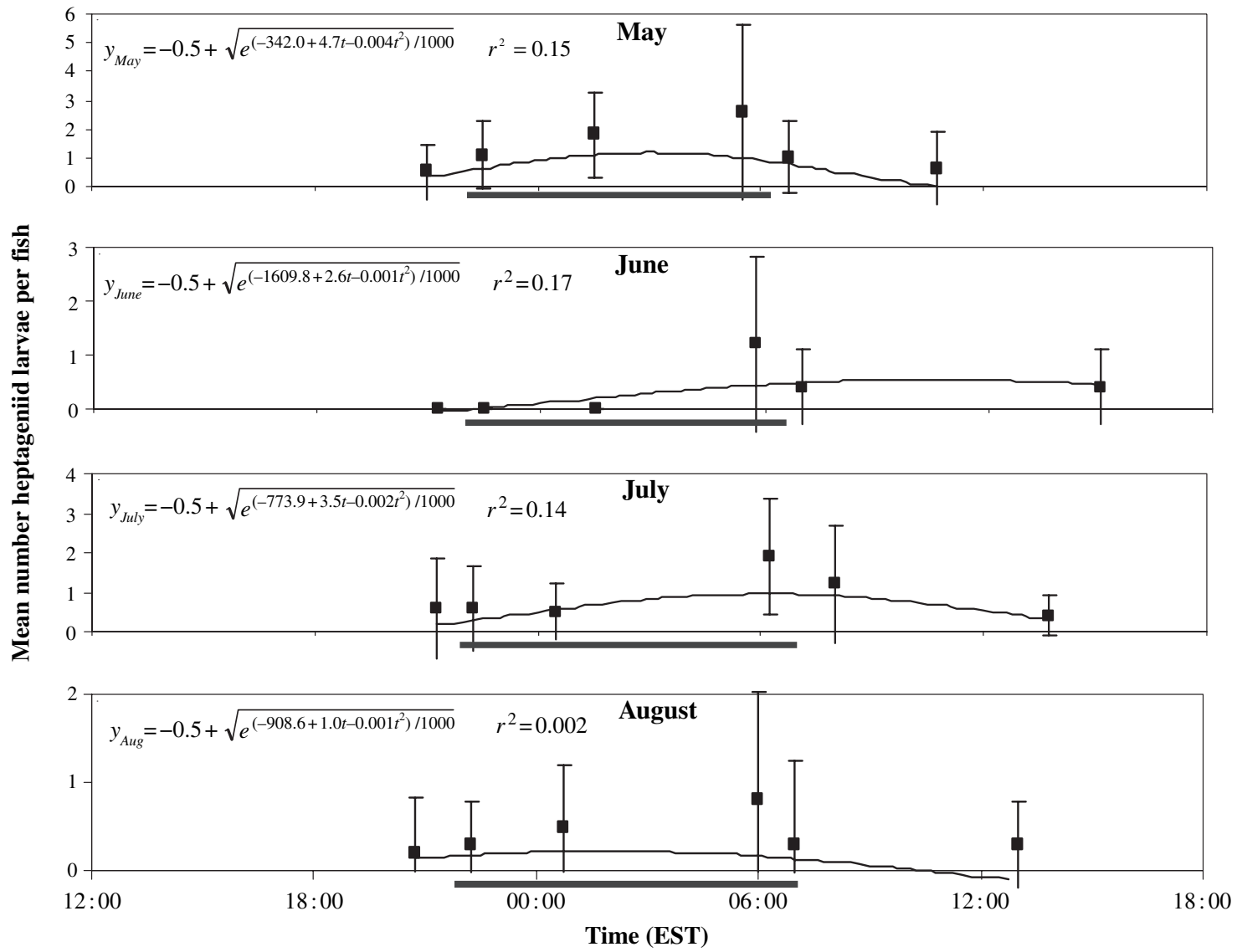

Fig. 5 Heptageniidae larvae in diets of the round goby from the Flint River on a diel basis by date (16/17 May, 28/29 June, $30 / 31$ July, and 22/23 August 1998). For all graphs, horizontal black bars along the bottom indicate night. Points are the mean number per stomach \pm standard deviation $\left(n=10\right.$ fish). Data were $\ln (x+1.0)^{2}$ transformed for analysis, then back-transformed for the graphs. Curves represent the regression curve for each month, where $t=$ time factor and $t^{2}=$ curvature factor. ANCOVA results: date $F_{3,233}=$ $7.9, P<0.001$; time $F_{1,233}=18.4, P<0.001$; curvature $F_{1,233}=15.8, P<0.001$.

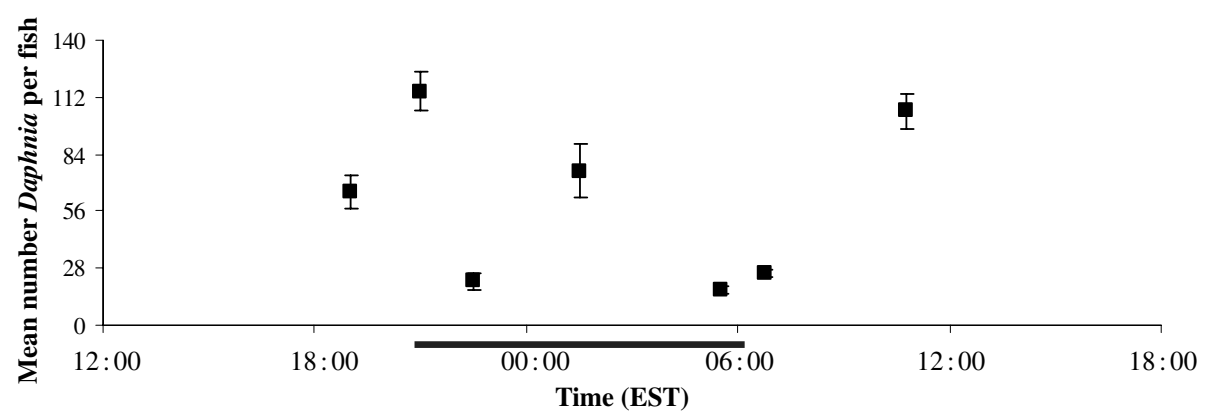

Fig. 6 Mean number $( \pm$ SE) of Daphnia in round goby diets from the Flint River from 16/17 May on a diel basis. Horizontal black bar along the bottom signifies night. $N=70$ fish. ANOVA: $F_{6,63}=3.70, P=0.003$ for time factor.

Flint River. Variation in feeding behaviour, including the use of prey from both the benthos and drift, in response to diel and seasonal prey availability, has also been recorded for the pumpkinseed sunfish (Lepomis gibbosus; Collins \& Hinch, 1993).
Although Daphnia were not always the most common zooplankton found in the drift, they were the most numerous in the diet. This may be due in part to the relatively larger size and behaviour of Daphnia. Cladocerans have a higher capture probability than 

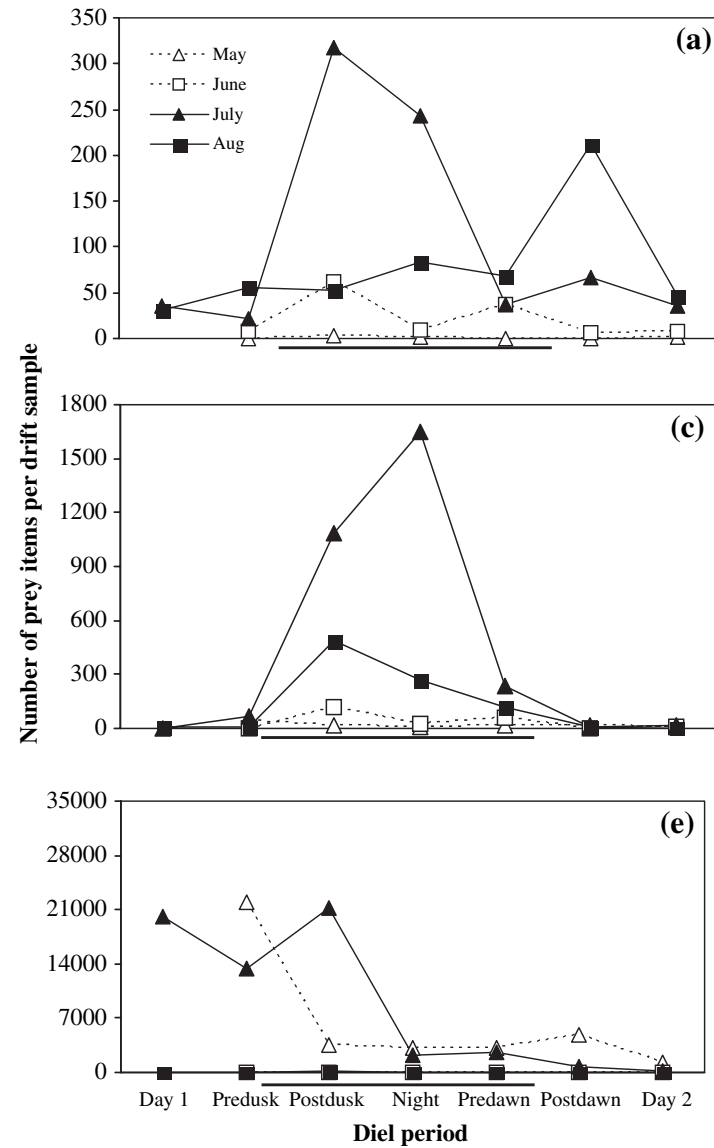
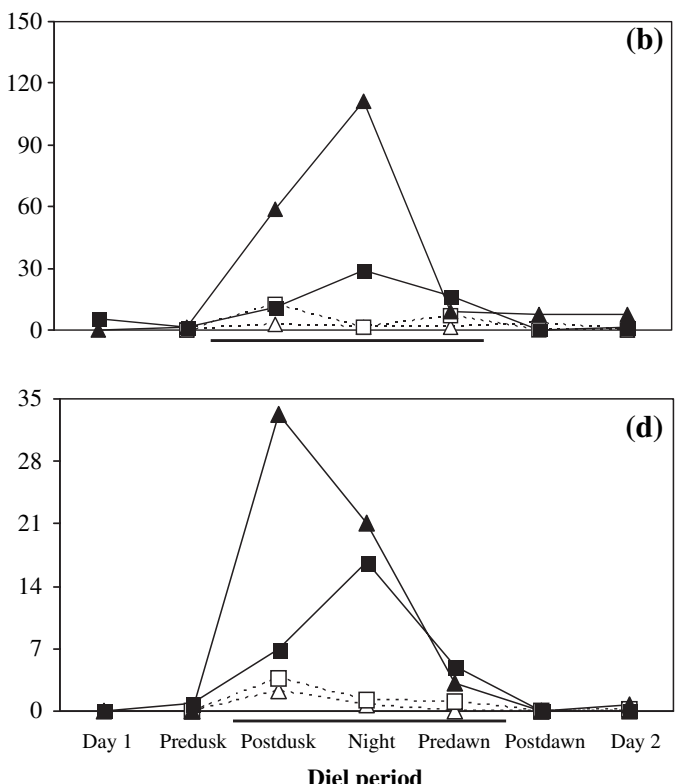

Diel period

Fig. 7 Number of prey items in drift samples from the Flint River on a diel basis by date (16/17 May, 28/29 June, 30/31 July and 22/23 August). For all graphs, horizontal black bars along the bottom signify night $(N=26)$. (a) Chironomid larvae, (b) Hydropsychid larvae, (c) Chironomid pupae, (d) Heptageniid larvae, (e) Daphnia.

copepods, allowing planktivores to capture cladocerans with more success (Drenner, Strickler \& O'Brien, 1978). The ability of copepods to avoid capture may account for their absence in the round goby diet.

Using the fish functional groups proposed by Matthews (1998), the round goby is both a benthicpicker, at least by day and drift-feeder and possibly benthic-picker by night. Therefore, the greatest diet overlap and potential for competition, would occur with other benthic-pickers, such as darters and sculpin. However, our Flint River site lacks a diverse native benthic fish assemblage. Whilst Leonardi \& Gruhn (2001) report that mottled sculpin (Cottus bairdi) and several darter species (Etheostoma spp.) can be found in the Flint River system, only blackside darters and stonecats were found during this study. Although this limits the ability to compare diets directly, prey choice of the round goby indicates the potential for diet overlap with native benthic fish.
During the day, the round goby chose prey that were abundant, exposed and active. This is similar to Etheostoma darters, which feed on a variety of benthic invertebrates, including larval chironomids, mayflies and stoneflies (Smart \& Gee, 1979; Greenberg, 1991). Etheostoma are presumably visual feeders and forage primarily during the day (Roberts \& Winn, 1962; Greenberg, 1991). At night, round gobies fed on prey that were conspicuously active, indicating that they are attracted by prey movement. The round goby has been shown to feed effectively at night presumably using its lateral line system (Jude et al., 1995). Cottus bairdi and other sculpins feed nocturnally on benthic invertebrates (Hoekstra \& Janssen, 1985; Greenberg, 1991). Hoekstra \& Janssen (1985) concluded that mottled sculpin use their lateral line system to detect prey at night and demonstrated that blinded fish could locate inert objects moving in an artificial stream. 
Catfishes of the genus Noturus also feed at night on a variety of aquatic invertebrates (Becker, 1983). However, French \& Jude (2001) reported that although diets of round gobies and northern madtoms (N. stigmosus) were similar in areas of the St Clair River, which flows from Lake Huron to Lake Erie, less potential for competition may exist. In the dark, Noturus species can detect prey using their well developed chemosensory and electrosensory systems. There may be very interesting trophic interactions between round gobies and catfishes. Although stonecats were present in the Flint River, an insufficient number was collected for diet comparison with round gobies.

Additionally, because the round goby feeds from the drift, there is potential for diet overlap with epibenthic Percina darters, whose diet includes midge and caddisfly larvae and baetid and heptageniid nymphs (Smart \& Gee, 1979; Greenberg, 1991). According to 1997 Michigan DNR data, blackside darters were the most frequent fish found at a monitoring site $1-\mathrm{km}$ upstream from our site (Leonardi \& Gruhn, 2001). In our 1997 and 1998 sampling, blackside darters accounted for $6 \%$ and $2 \%$, respectively, of the total catch at the study site.

The success of the round goby in the Flint River may be due in part to the absence of a diverse benthic fish assemblage. It has been shown that biological assemblages with higher species diversity are less susceptible to invasion (Lodge, 1993; Tilman, 1997; Cohen \& Carlton, 1998). Studies indicate that this may be because of a more complete and effective use of resources and strong interspecific interactions (Case, 1990; Stachowicz, Whitlach \& Osman, 1999). Redundancy of species in the same trophic level, such as in a rich benthic fish assemblage, leads to lower invasibility and a lower likelihood of replacement of native fish (Naeem \& Li, 1997). Additionally, in aquatic systems, invasion occurs more readily in areas that are impacted by humans (Ross, 1991). The section of the Flint River studied flows through farmland with a forested riparian zone and lies between two dams, so there have been anthropogenic impacts (Leonardi \& Gruhn, 2001). Additionally there is a history of fish invasions and stocking programs. These factors also may have facilitated the establishment of round gobies.

Our study clearly documents that, despite morphology indicative of being a feeding specialist, the round goby in fact has a diverse feeding capability and can be included as an example of an invader with a broad diet along with the other characteristics listed by Ricciardi \& Rasmussen (1998). Indeed, the abundance of round gobies in the Flint River suggests that the success of the round goby invasion is not necessarily contingent on zebra mussels. Hence citing their success as evidence of an 'invasional meltdown', the situation in which one species facilitates the invasion of other species (Simberloff \& Von Holle, 1999), must be done with caution. The round goby invaded the Great Lakes basin shortly after zebra mussels and was discovered in the St Clair River, between Lakes Huron and Erie, near where zebra mussels were first discovered. Because the round goby typically has been found in areas with abundant zebra mussels and because zebra mussels form a substantial portion of their diet in such places (Jude et al., 1995; French \& Jude, 2001; Janssen \& Jude, 2001) it has been argued that zebra mussels facilitate round goby success as well as that of other invasive species (Ricciardi, 2001).

The family Gobiidae is the most speciose marine family, with at least 1875 species. It's ranking is comparable with the most speciose freshwater family, the Cyprinidae, with about 2000 species (Moyle \& Cech, 2000). Gobiids are extremely adaptable, frequently adapting to freshwater especially on oceanic islands. This ability to adapt to new environments has probably fostered the unusual degree of speciation. The round goby may be a prime example of gobiid adaptability; despite specialisations for feeding on bivalves (Ghedotti et al.,1995) they are successfully being sustained on a mainly insect diet in the Flint River. A wide breadth of diet is a frequently cited quality of a successful invasive species (Ricciardi \& Rasmussen, 1998).

It has been argued that a diverse native population can minimise or deter an invasion (Tilman, 1997; Stachowicz et al., 1999). As the round goby expands its range we may learn whether a diverse ensemble of Etheostoma darters, perhaps in concert with sculpins, can prevent or minimise a round goby invasion or whether the round goby will extirpate many of these species.

\section{Acknowledgments}

We would like to thank National Sea Grant for funding this study. We are grateful to Terry Grande and John Dettmers for their review and assistance 
with the study as members of Stephanie Carman's thesis committee. Julie Ryan, Kirby Wolfe, Grace Kilbane, Patrice Charlebois, Indira Bhattacharji, Reese Rominski, Stephen Hensler, Nicole Vidales and Nia Haller provided valuable field assistance.

\section{References}

Becker G.C. (1983) The Fishes of Wisconsin. University of Wisconsin Press, Madison, Wisconsin.

Bergey E.A. \& Ward J.V. (1989) Upstream-downstream movements of aquatic invertebrates in a Rocky Mountain stream. Hydrobiologia, 185, 71-82.

Case T.J. (1990) Invasion resistance arises in strongly interacting species-rich model competition communities. Proceedings of the National Academy of Sciences, USA, 87, 9610-9614.

Charlebois P.M., Corkum L.D., Jude D.J. \& Knight C. (2001) The round goby (Neogobius melanostomus) invasion: current research and future needs. Journal of Great Lakes Research, 27, 263-266.

Charlebois P.M., Marsden J.E., Goettel R.G., Wolfe R.K., Jude D.J. \& Rudnicka S. (1997) The Round Goby, Neogobius melanostomus (Pallas), a Review of European and North American Literature. Illinois-Indiana Sea Grant Program and Illinois Natural History Survey. INHS Special Publication No. 20.

Cohen A.N. \& Carlton J.T. (1998) Accelerating invasion rate in a highly invaded estuary. Science, 279, 555-558.

Collins N.S. \& Hinch S.G. (1993) Diel and seasonal variation in foraging activities of pumpkinseeds in an Ontario pond. Transactions of the American Fisheries Society, 122, 357-365.

Drenner R.W., Strickler J.R. \& O'Brien W.J. (1978) Capture probability: the role of zooplankter escape in the selective feeding of planktivorous fish. Journal of the Fisheries Research Board of Canada, 35, 13701373.

Dubs D.O.L. \& Corkum L.D. (1996) Behavioral interactions between round gobies (Neogobius melanostomus) and mottled sculpins (Cottus bairdi). Journal of Great Lakes Research, 22, 838-844.

Elliott J.M. (1968) The daily activity patterns of mayfly nymphs (Ephemeroptera). Journal of Zoology (Series A), 155, 201-221.

French J.R.P. \& Jude D.J. (2001) Diets and diet overlap of nonindigenous gobies and small benthic native fishes co-inhabiting the St Clair River, Michigan. Journal of Great Lakes Research, 27, 300-311.

Ghedotti M.J., Smihula J.C. \& Smith G.R. (1995) Zebra mussel predation by round gobies in the laboratory. Journal of Great Lakes Research, 21, 665-669.
Greenberg L.A. (1991) Habitat use and feeding behavior of thirteen species of benthic stream fishes. Environmental Biology of Fishes, 31, 389-401.

Hoekstra D. \& Janssen J. (1985) Non-visual feeding behavior of the mottled sculpin, Cottus bairdi, in Lake Michigan. Environmental Biology of Fishes, 12, 111-117.

Janssen J. \& Jude D.J. (2001) Recruitment failure of mottled sculpin Cottus bairdi in Calumet Harbor, southern Lake Michigan, induced by the newly introduced round goby Neogobius melanostomus. Journal of Great Lakes Research, 27, 319-328.

Johnson J.H. \& Dropkin D.S. (1993) Diel variation in diet composition of a riverine fish community. Hydrobiologia, 271, 149-158.

Jude D.J. (2001) Round and tubenose gobies: 10 years with the latest Great Lakes phantom menace. Dreissena, 11, 1-14.

Jude D.J. \& DeBoe S. (1996) Possible impact of gobies and other introduced species on habitat restoration efforts. Canadian Journal of Fisheries and Aquatic Sciences, 53 (Suppl. 1), 136-141.

Jude D.J., Janssen J. \& Crawford G. (1995) Ecology, distribution and impact of the newly introduced round and tubenose gobies on the biota of the St Clair and Detroit Rivers. In: The Lake Huron Ecosystem: Ecology, Fisheries, and Management (Eds M. Munawar, T. Edsall \& J. Leach), pp. 447-460. Ecovision World Monograph Series, S.P.B. Academic Publishing, the Netherlands.

Keast A. \& Welsh L. (1968) Daily feeding periodicities, food uptake rates and dietary changes with hour of day in some lake fishes. Journal of the Fisheries Research Board of Canada, 25, 1133-1144.

Kobegenova S.S. \& Dzhumaliyev M.K. (1992) Morphological and functional characteristics of the digestive system of some gobies (Gobiodei). Journal of Ichthyo$\log y, 32,94-104$.

Laughlin D.R. \& Werner E.E. (1980) Resource partitioning in two coexisting sunfish: pumpkinseed (Lepomis gibbosus) and northern longear sunfish (Lepomis megalotis peltastes). Canadian Journal of Fisheries and Aquatic Sciences, 37, 1411-1420.

Leonardi J.M. \& Gruhn W.J. (2001) Flint River Assessment. Michigan Department of Natural Resources, Fisheries Division, Special Report 17. Ann Arbor, Michigan.

Lodge D.M. (1993) Biological invasions: lessons for ecology. Trends in Ecological Evolution, 8, 133-137.

Lyman F.E. (1945) Reactions of certain nymphs of Stenonema (Ephemeroptera) to light as related to habitat preference. Annals of the Entomological Society of America, 38, 234-236.

Matthews W. J. (1998) Patterns in Freshwater Fish Ecology. Chapman and Hall, New York. 
Miller P.J. (1986) Gobiidae. In: Fishes of the Northeast Atlantic and Mediterranean (Eds P.J.P. Whitehead, M.L. Bauchot, J.C. Hureau, J. Nielsen \& E. Tortonese), pp. 1019-1095. UNESCO, Paris.

Moyle P.B. \& Cech J.J. (2000) Fishes: an Introduction to Ichthyology. Prentice-Hall, Upper Saddle River, NJ.

Moyle P.B., Li H.W. \& Barton B.A. (1986) In: The Frankenstein Effect: Impact of Introduced Fishes on Native Fishes in Northern America. Fish Culture in Fisheries Management (Ed. R.H. Stround), pp. 415-426. American Fisheries Society, Fish Culture Section and Fisheries Management Section, Bethesda, MD.

Naeem S. \& Li S. (1997) Biodiversity enhances ecosystem reliability. Nature, 390, 507-508.

Nelson J. (1994) Fishes of the World, 3rd edn. John Wiley and Sons, New York, NY.

Pálmen E. (1955) Diel periodicity of pupal emergence in natural populations of some chironomids. Annales Zoologici Societatis Zoologicae Botanicae Fennicae 'Vana$m o^{\prime}, \mathbf{1 7}, 1-30$.

Ray W.J. \& Corkum L.D. (1997) Predation of zebra mussels by round gobies, Neogobius melanostomus. Environmental Biology of Fishes, 50, 267-273.

Ricciardi A. (2001) Facilitative interactions among aquatic invaders: is an 'invasional meltdown' occurring in the Great Lakes? Canadian Journal of Fisheries and Aquatic Sciences, 58, 2513-2525.

Ricciardi A. \& Rasmussen J.B. (1998) Predicting the identity and impact of future biological invaders: a priority for aquatic resource management. Canadian Journal of Fisheries and Aquatic Sciences, 55, 1759-1765.

Roberts N.J. \& Winn H.E. (1962) Utilization of the senses in feeding behavior of the johnny darter, Etheostoma nigrum. Copeia, 1962, 567-570.
Prey behaviour and feeding of round gobies

Ross S.T. (1986) Resource partitioning in fish assemblages: a review of field studies. Copeia, 1986, 352-388.

Ross S.T. (1991) Mechanisms structuring stream fish assemblages: are there lessons from introduced species? Environmental Biology of Fishes, 30, 359-368.

Saint-Jacques N., Harvey H.H. \& Jackson D.A. (2000) Selective foraging in the white sucker (Catostomus commersoni). Canadian Journal of Zoology, 78, 1320-1331.

Simberloff D. \& Von Holle B. (1999) Positive interactions of nonindigenous species: invasional meltdown? Biological Invasions, 1, 21-32.

Simonovic P., Paunovic M. \& Popovic S. 2001. Morphology, feeding, and reproduction of the round goby, Neogobius melanostomus (Pallas), in the Danube River Basin, Yugoslavia. Journal of Great Lakes Research, 27, 281-289.

Smart H.J. \& Gee J.H. (1979) Coexistence and resource partitioning in two species of darters (Percidae), Etheostoma nigrum and Percina maculata. Canadian Journal of Zoology, 57, 2061-2071.

Stachowicz J.J., Whitlach R.B. \& Osman R.W. (1999) Species diversity and invasion resistance in a marine ecosystem. Science, 286, 1577-1579.

SYSTAT 5.03. (1993) Systat, Inc. Evanston, Illinois.

Tanaka H. (1960) On the daily change of the drifting of benthic animals in stream, especially on the types of daily changes observed in taxonomic groups of insects. Bulletin of the Freshwater Fishes Research. Laboratory, Tokyo, 9, 13-24.

Tilman D. (1997) Community invasibility, recruitment limitation, and grassland biodiversity. Ecology, 78, 81-92.

(Manuscript accepted 13 January 2006) 